This item was submitted to Loughborough's Research Repository by the author.

Items in Figshare are protected by copyright, with all rights reserved, unless otherwise indicated.

\title{
Mechanical behaviour of grains in SnAgCu solder joints
}

PLEASE CITE THE PUBLISHED VERSION

PUBLISHER

(C) IEEE

VERSION

VoR (Version of Record)

LICENCE

CC BY-NC-ND 4.0

REPOSITORY RECORD

Gong, Jicheng, Changqing Liu, Paul P. Conway, and Vadim V. Silberschmidt. 2019. "Mechanical Behaviour of Grains in Snagcu Solder Joints". figshare. https://hdl.handle.net/2134/5338. 
This item was submitted to Loughborough's Institutional Repository (https://dspace.lboro.ac.uk/) by the author and is made available under the following Creative Commons Licence conditions.

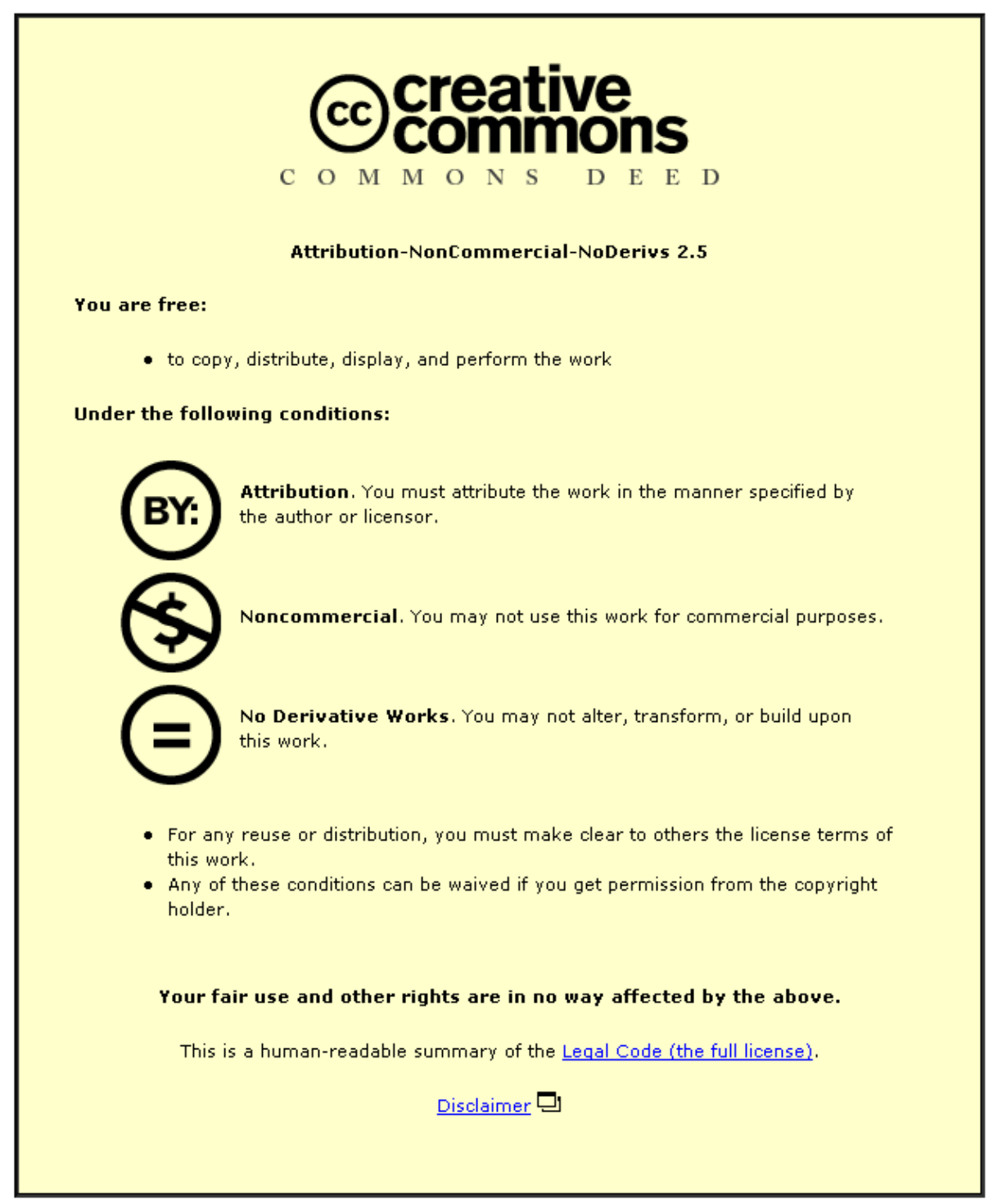

For the full text of this licence, please go to: http://creativecommons.org/licenses/by-nc-nd/2.5/ 


\section{Mechanical Behaviour of Grains in SnAgCu Solder Joints}

Jicheng Gong, Changaing Liu,

Paul P. Conway and Vadim V. Silberschmidt

Wolfson School of Mechanical and Manufacturing Engineering

Loughborough University, UK 


\section{Background}

- Lead-free solder

- Thermal induced load due to mismatch of CTE

- Typical method to predict reliability of solder joints:

- Modelling mechanical behaviour of solder joints in electronics under thermal cyclic load through FEA

- Predict the number of cycles to failure based on fatigue model (eg. Coffin-mansion equation)

- A accurate constitutive model to describe mechanical behaviour and corresponding fatigue model are required 


\section{Microstructure of a micro-SnAgCu joint}

- Most constitutive model and fatigue model are based on bulk specimens

- A micro- joint contain few grains

- $\quad \beta-S n$, the matrix of SnAgCu solder, has a contracted body-centred tetragonal structure, promising considerable anisotropic hehaviour
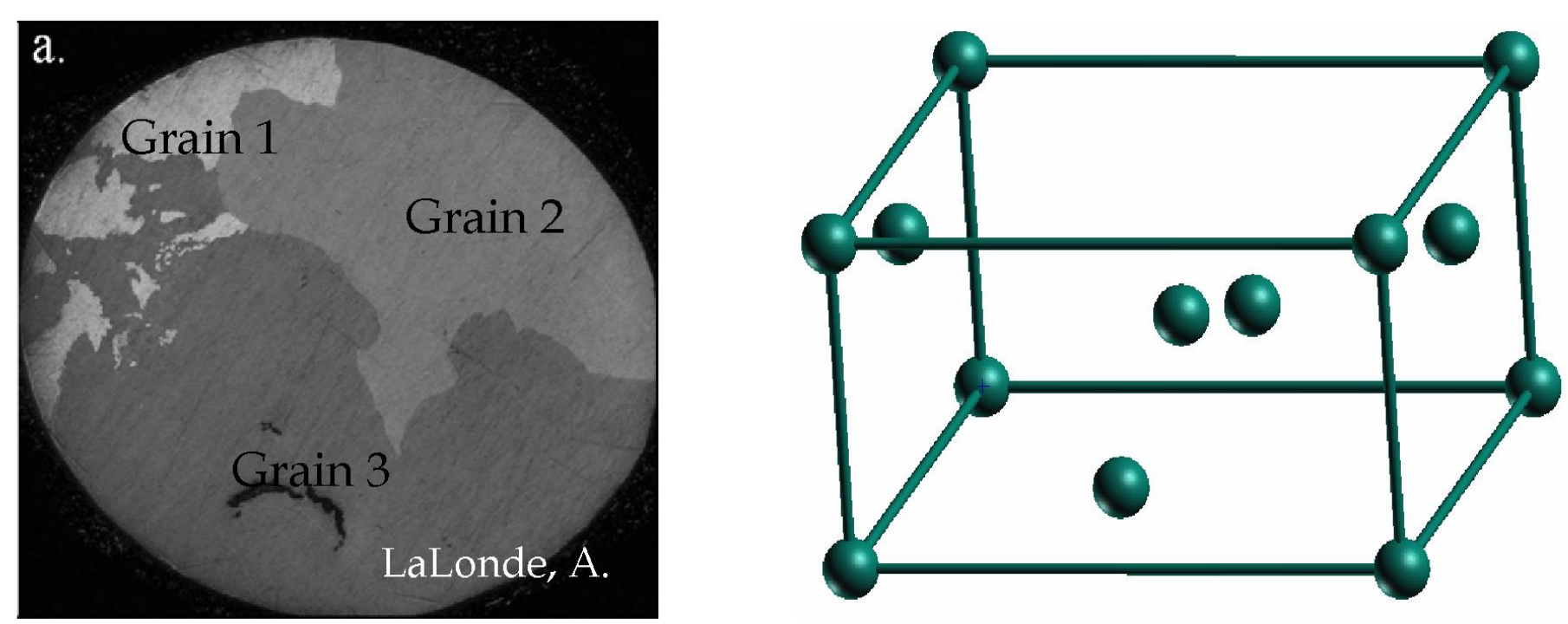


\section{Anisotropic mechanical behaviour of SnAgCu single crystal}

- Three types of anisotropic behaviour are expected: elastic behaviour, thermal expansion and inelastic behaviour

- The former two can refer to Matin, M. A. et al.

- This presentation focuses on the last one

- Both the size and cooling condition's effect on grain features are studied

- A shearing mechanical test is performed to study these features on inelastic behaviour of SnAgCu solder joints

- Matin, M. A. et al, "Correlation between thermal fatigue and thermal anisotropy in a Pb-free solder alloy," Scripta Mater., Vol. 53, No. 8 (2005), pp. 927-932 


\section{Sample preparation}

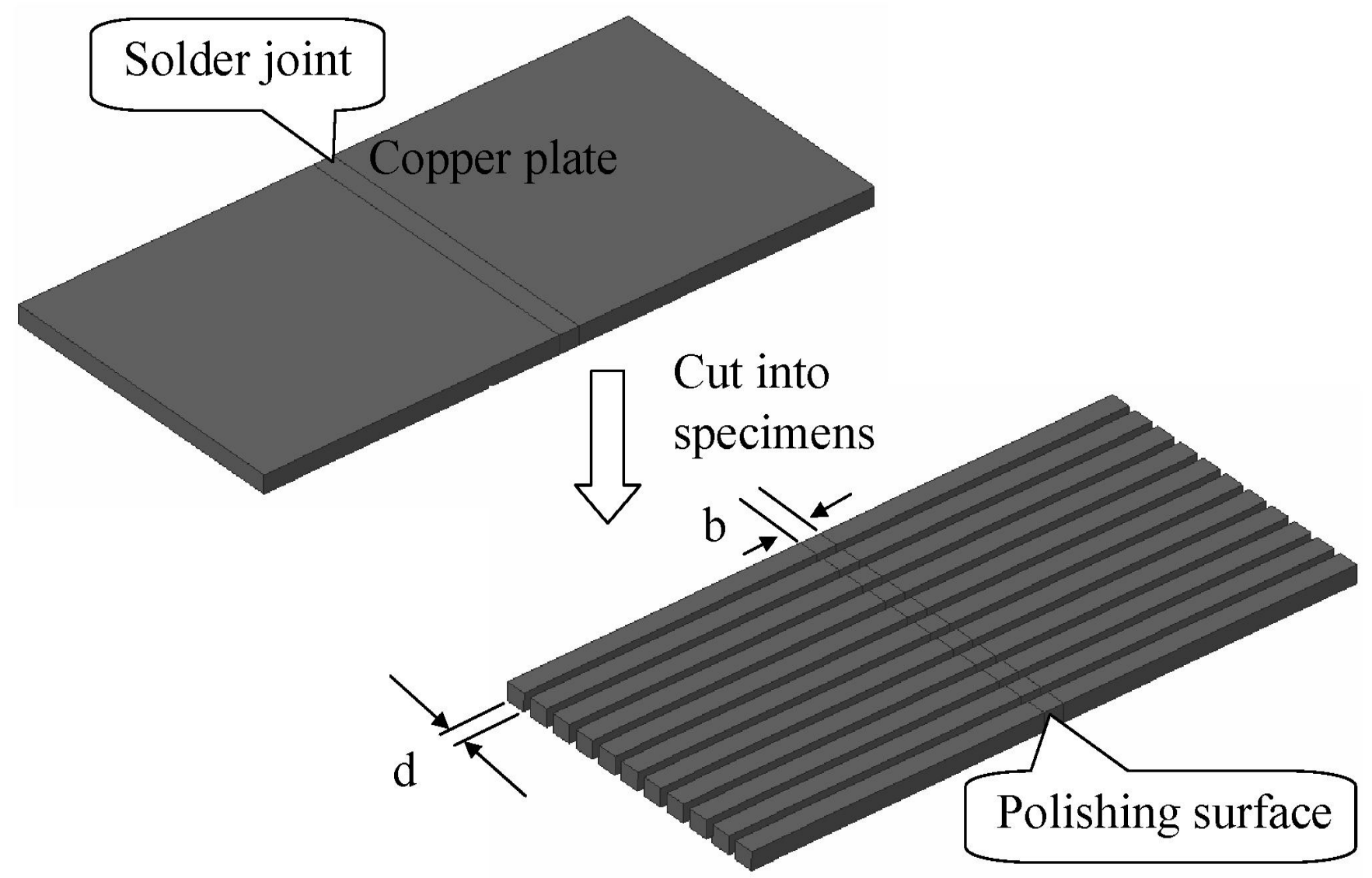

- $d=1 \mathrm{~mm}, b=0.1$ and $1 \mathrm{~mm}$, respectively, which corresponds to solder joints of BGA and flip chip 


\section{Temperature profile}

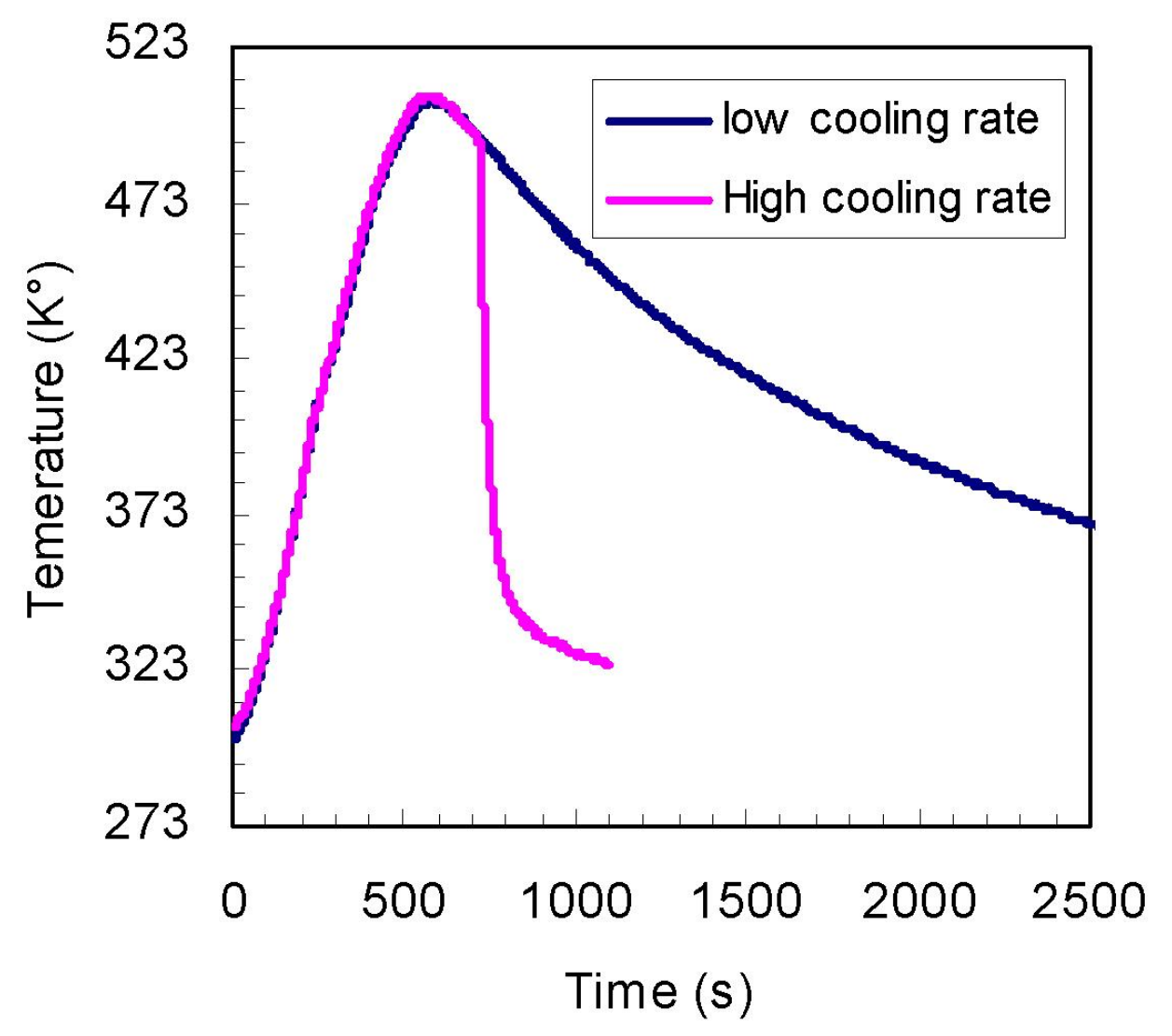

- The cooling rates near the melting point are $0.13^{\circ} \mathrm{K} / \mathrm{s}$ and $4.5^{\circ} \mathrm{K} / \mathrm{s}$, respectively. Their heating and cooling condition are the same before 718 s (around $493^{\circ} \mathrm{K}$ ) 


\section{$\underline{\text { Results }}$}

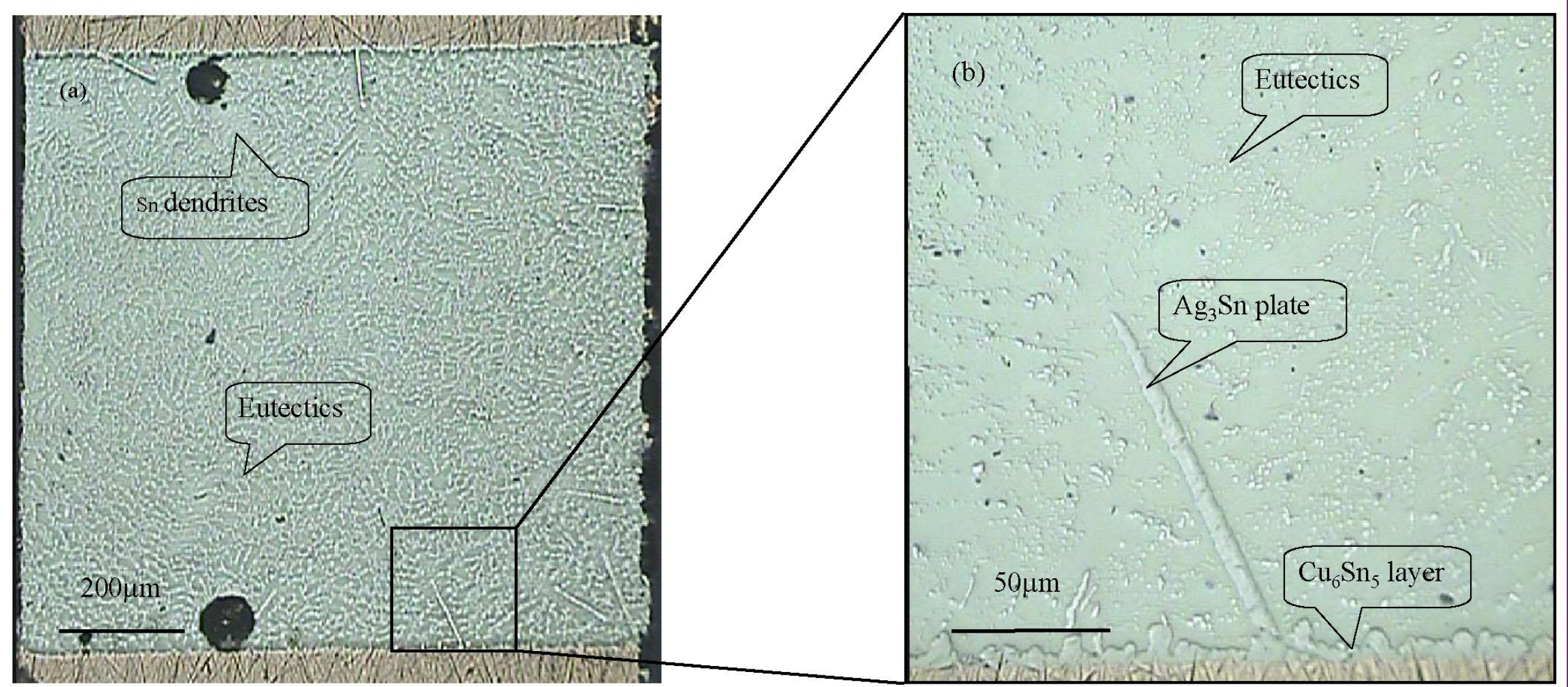

- A large joint $(b=965 \mu \mathrm{m})$ formed at the slow cooling rate $\left(0.13^{\circ} \mathrm{K} / \mathrm{s}\right)$. 


\section{Shearing test}
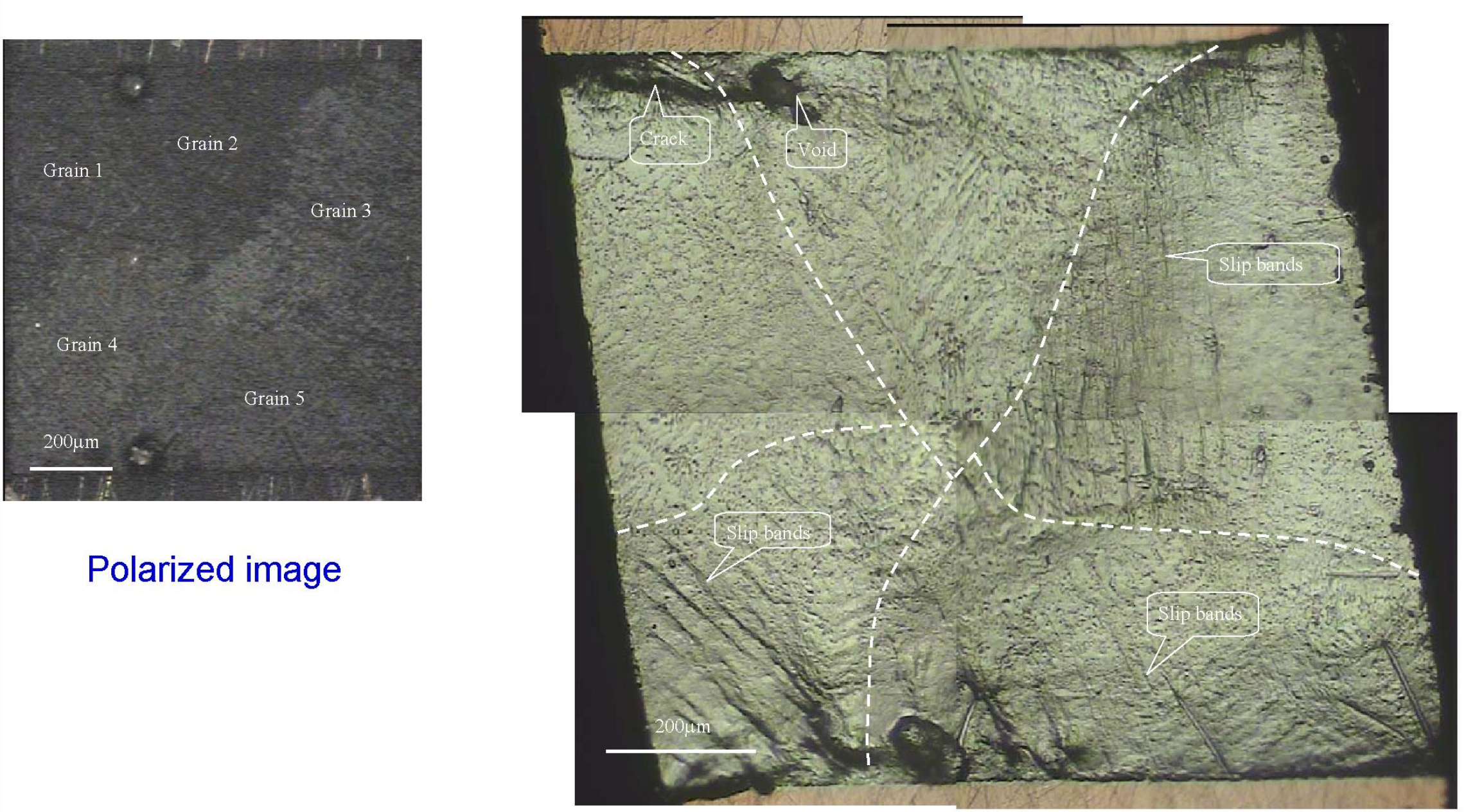

- A large joint $(b=965 \mu \mathrm{m})$ formed at the slow cooling rate $\left(0.13^{\circ} \mathrm{K} / \mathrm{s}\right)$.

\section{Polarized image}

A 


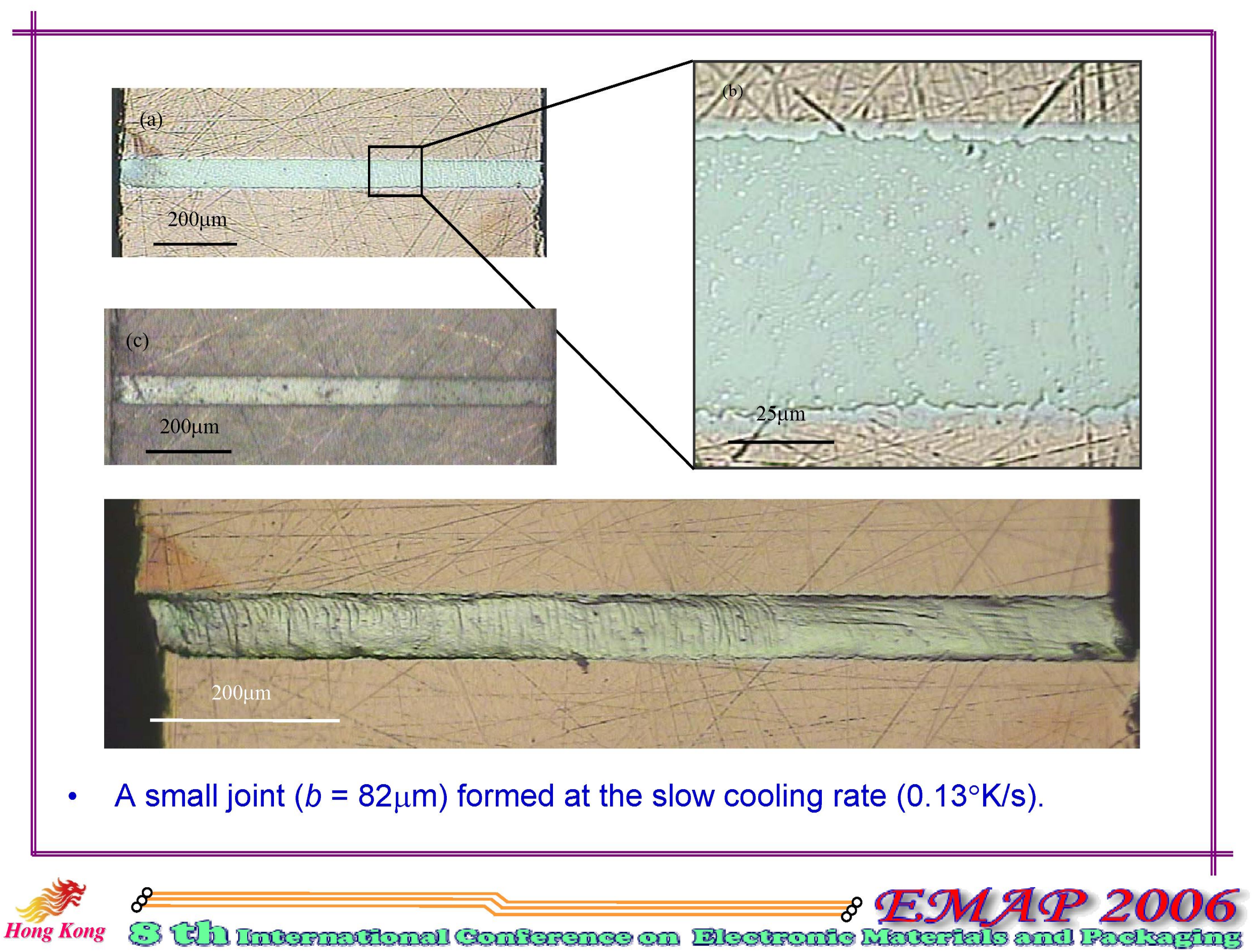




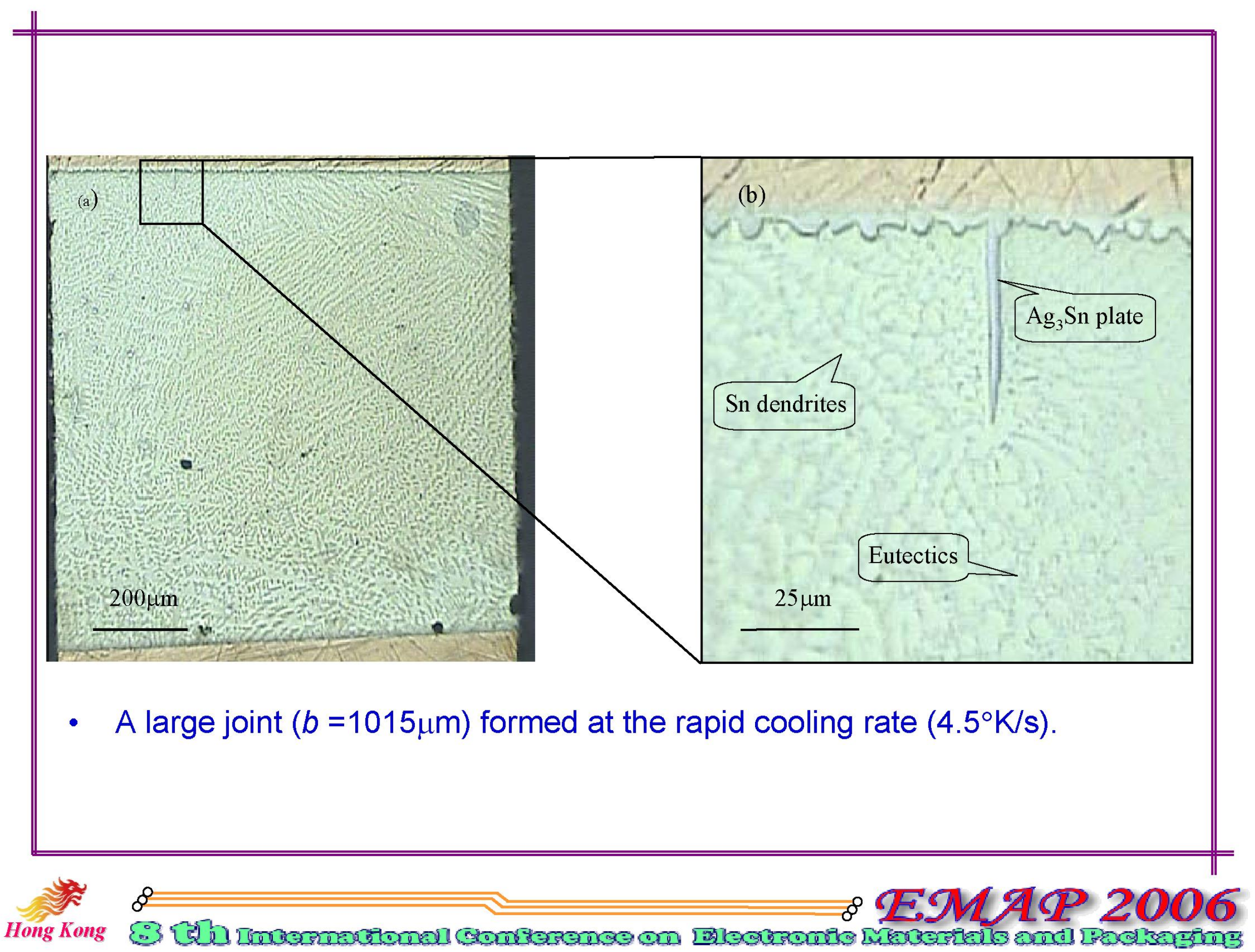




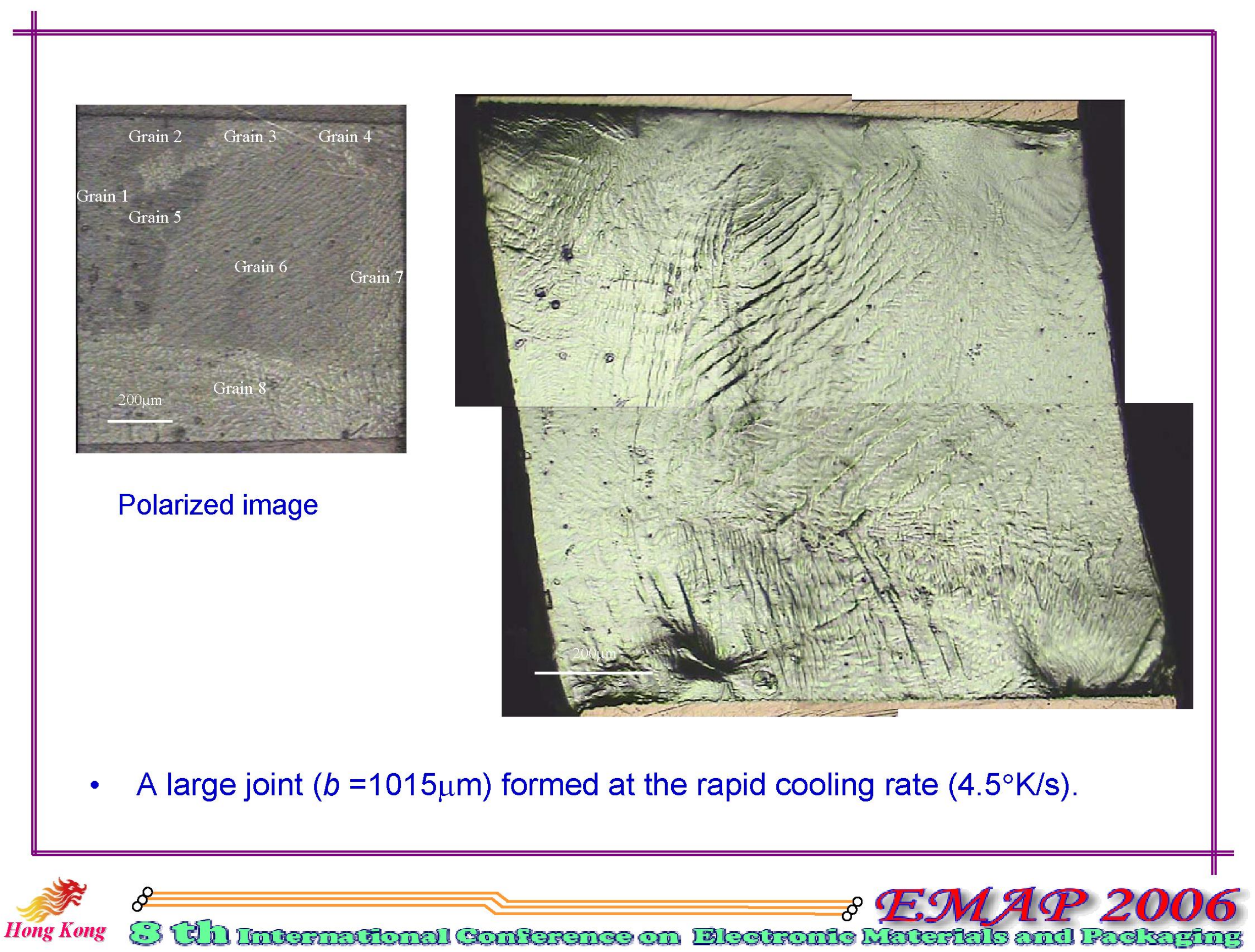




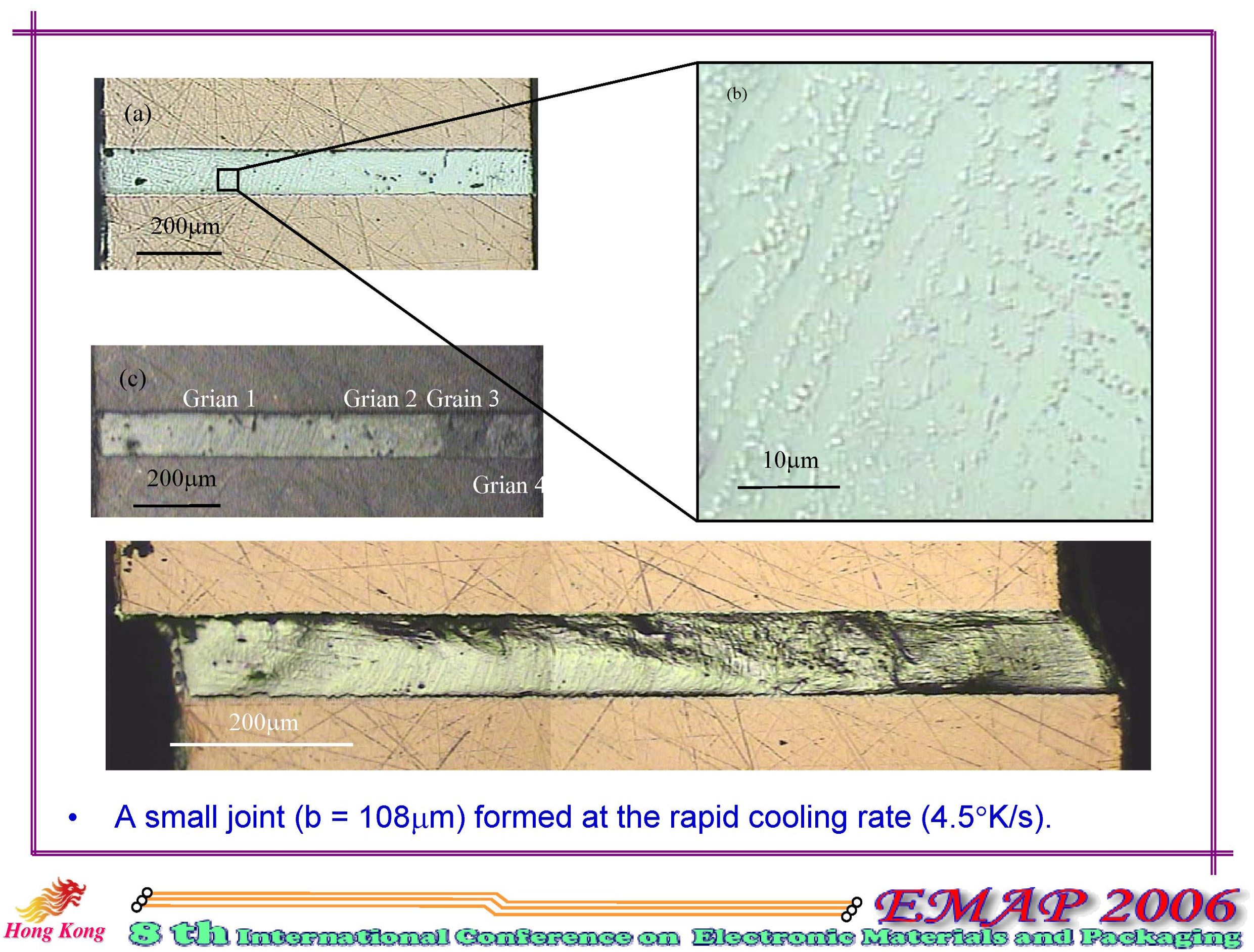




\section{Discussion}

- For bulk specimens, their mechanical behaviour results from the contribution of all grains. Their behaviour exhibits an average phenomena. Therefore, the constitutive model is isotropic and their fatigue life concentrate at certain value

- For a micro- joint, the mechanical behaviour depends on local microstructure. Therefore, their fatigue life distributes smoothly

- The reliability of micro- joints is determined by the weakest microstructure

- It important to proposed a model to describe this lattice orientationdependent behaviour

Distribution

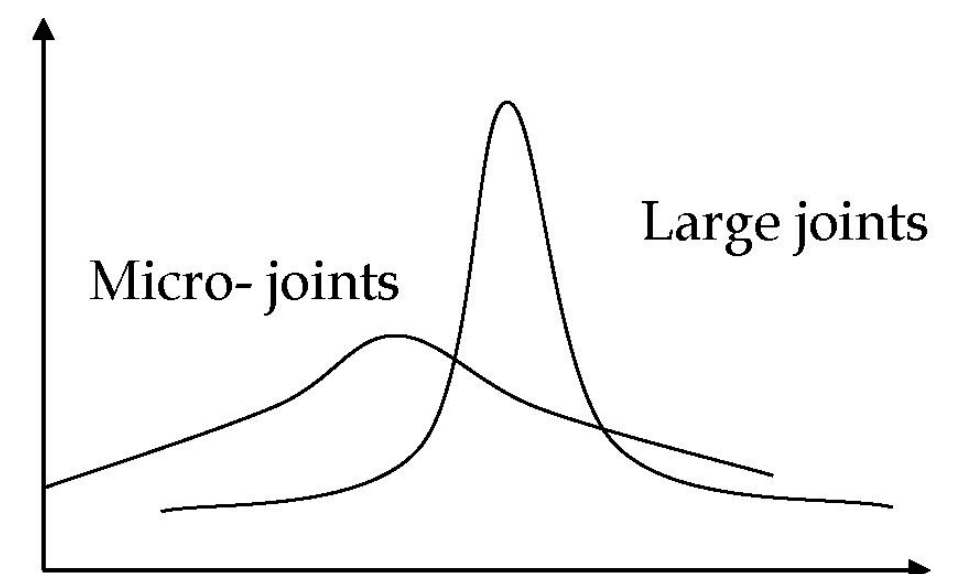

Cycles to failure 


\section{A constitutive model for SnAgCu micro -joints}

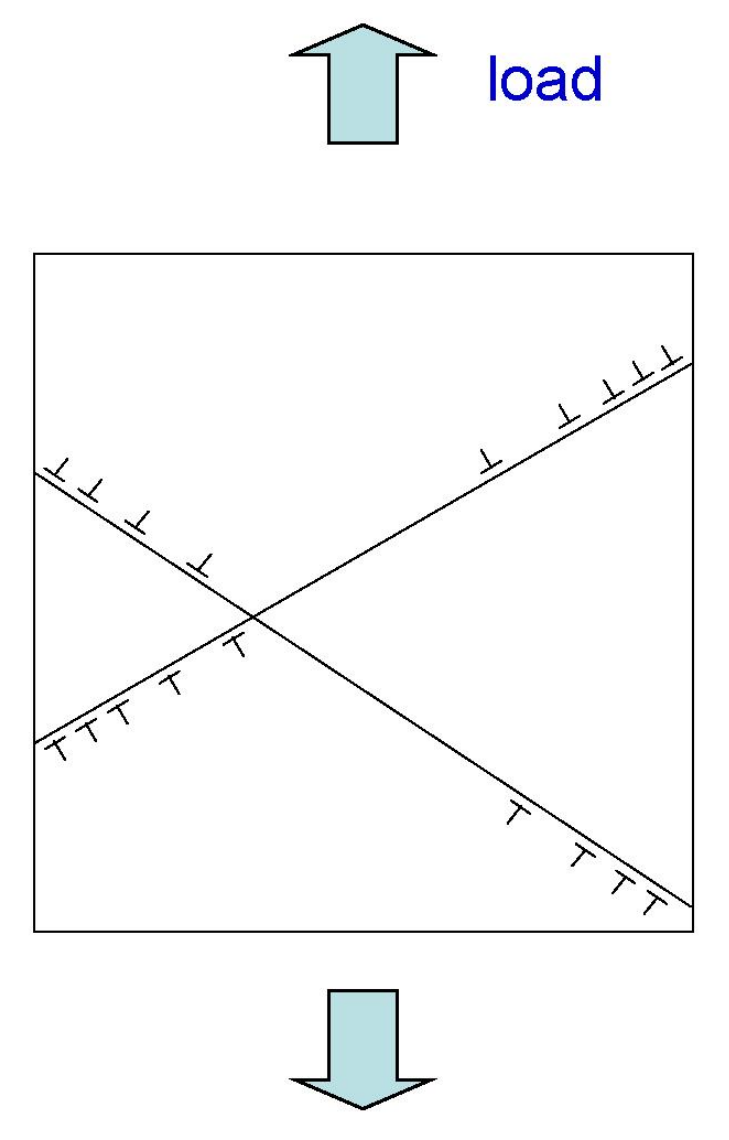

$$
\begin{aligned}
& \dot{\gamma}_{\alpha}=A_{\alpha}\left(\tau_{\alpha}\right)^{n} \exp \left(\frac{Q_{\alpha}}{R T}\right) \\
& \tau^{(\alpha)}=\mathbf{s}^{(\alpha)}: \boldsymbol{\sigma} \\
& \dot{\boldsymbol{\varepsilon}}_{1 \mathrm{~d}}=\sum_{\alpha=1}^{N} \dot{\gamma}_{\alpha} \mathbf{s}_{\alpha}
\end{aligned}
$$

S - Schmid tensor

- Certain slip systems can be activated during laoding

- The inelastic behaviour is the sum of deformation due to each slip system 


\section{Flip chip electronics: global model}
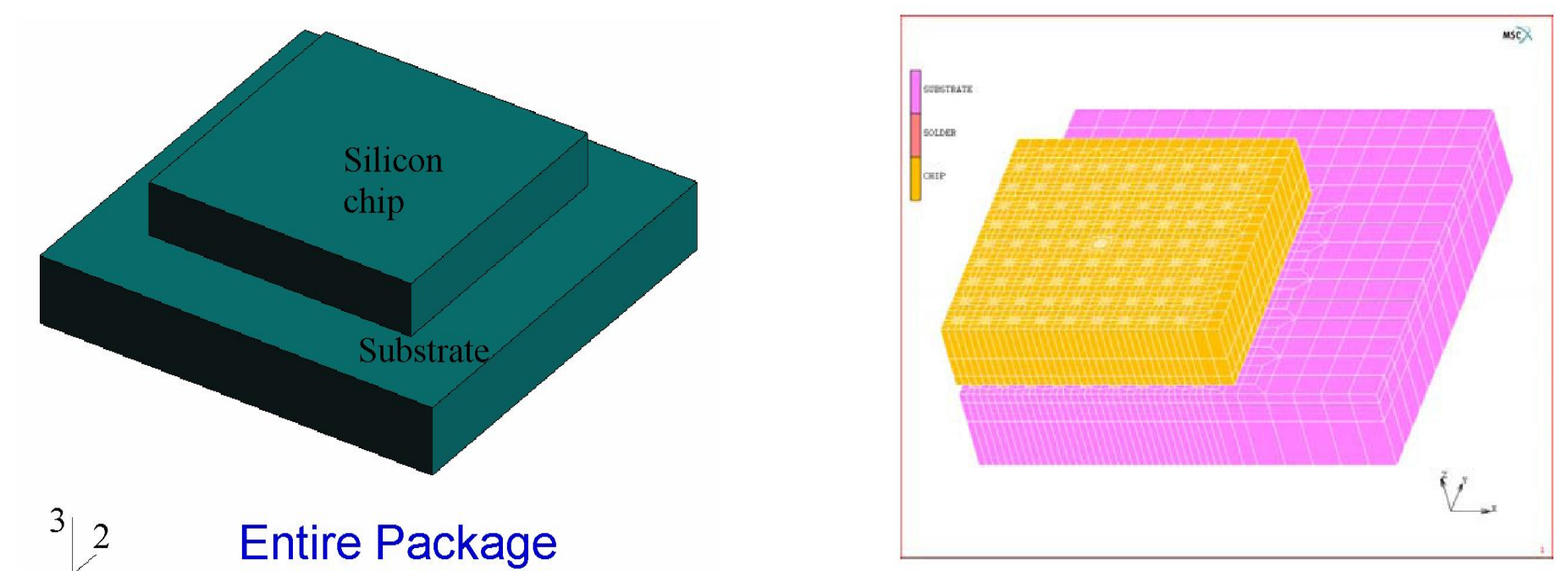

${ }^{3} L_{1} \quad$ Entire Package

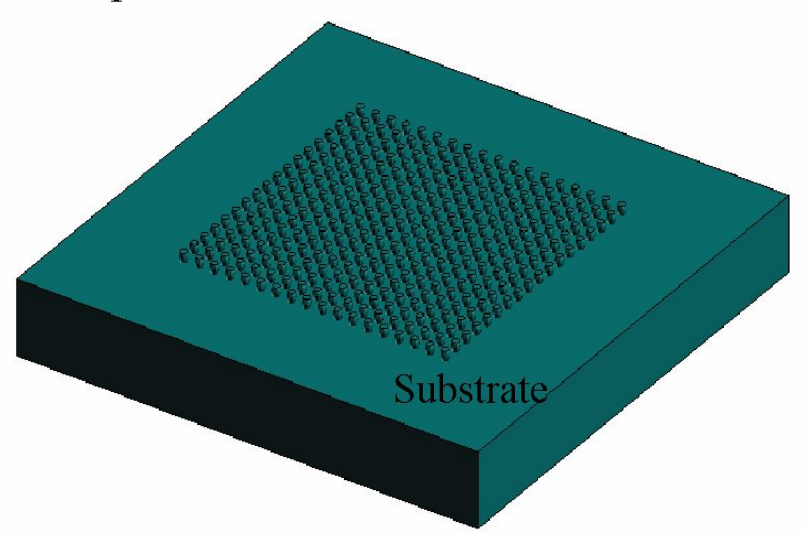

${ }^{3} Z_{1}^{2} \quad$ Without silicon chip

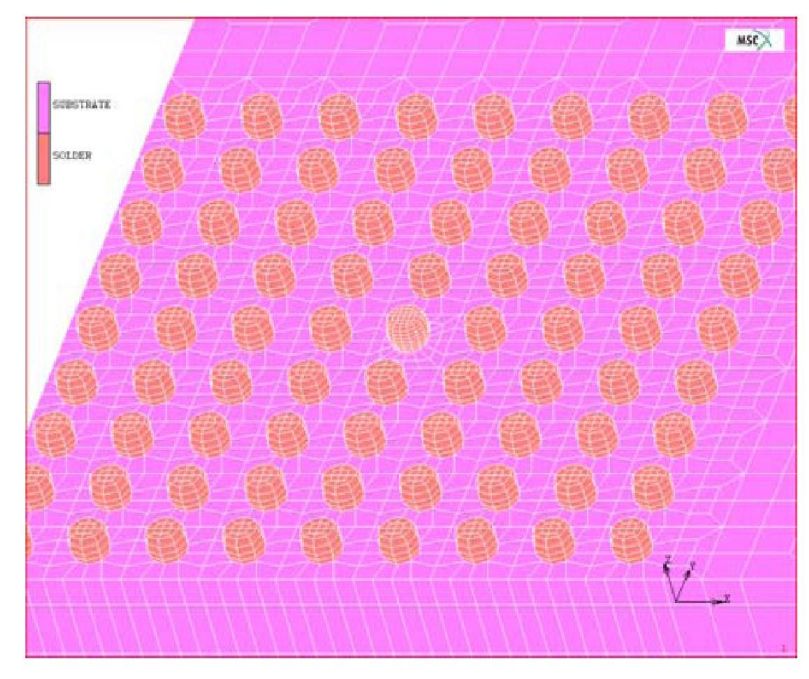

8 


\section{Deformation of the flip chip under thermal cyclic load}
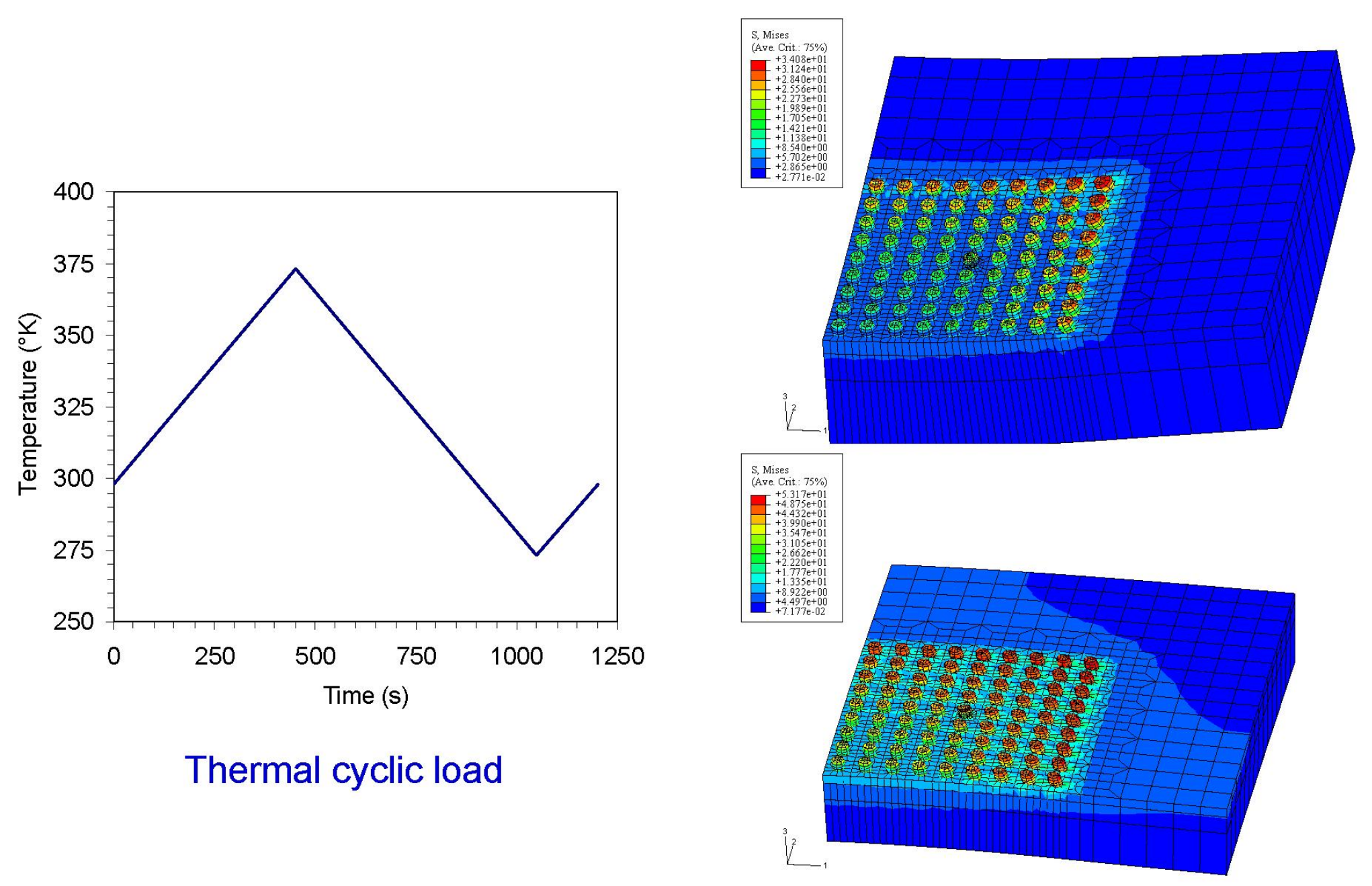

Equivalent stress

8

Thermal cyclic load 


\section{Simulation Results: submodel}

\section{Traditional model}

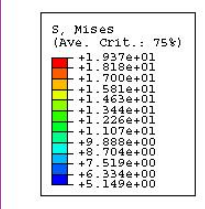

$L_{3}^{2}$

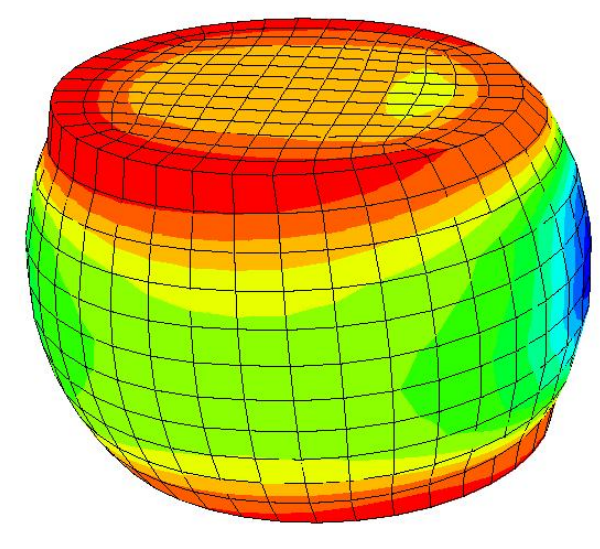

Single crystal joint
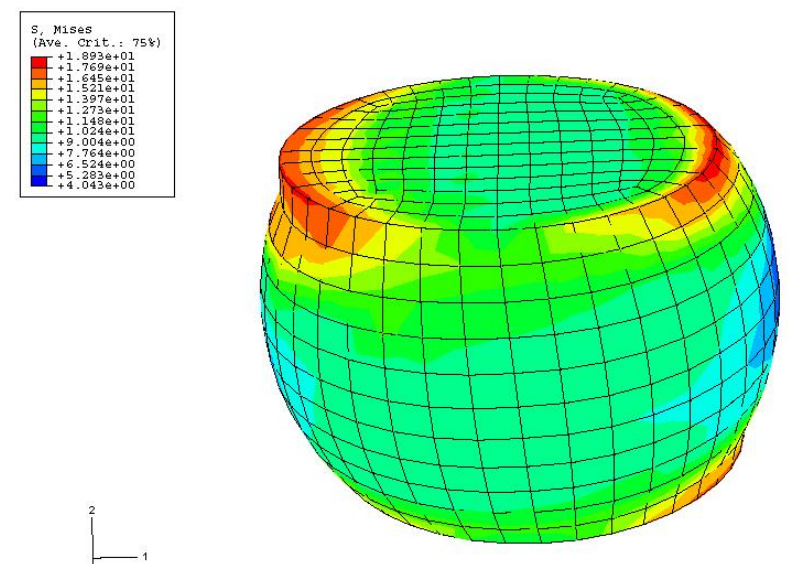

- The Mise equivalent stress gradient in single crystal is larger than that in traditional model based on bulk specimens 


\section{Stress components in single crystal joint with different grain orientation}
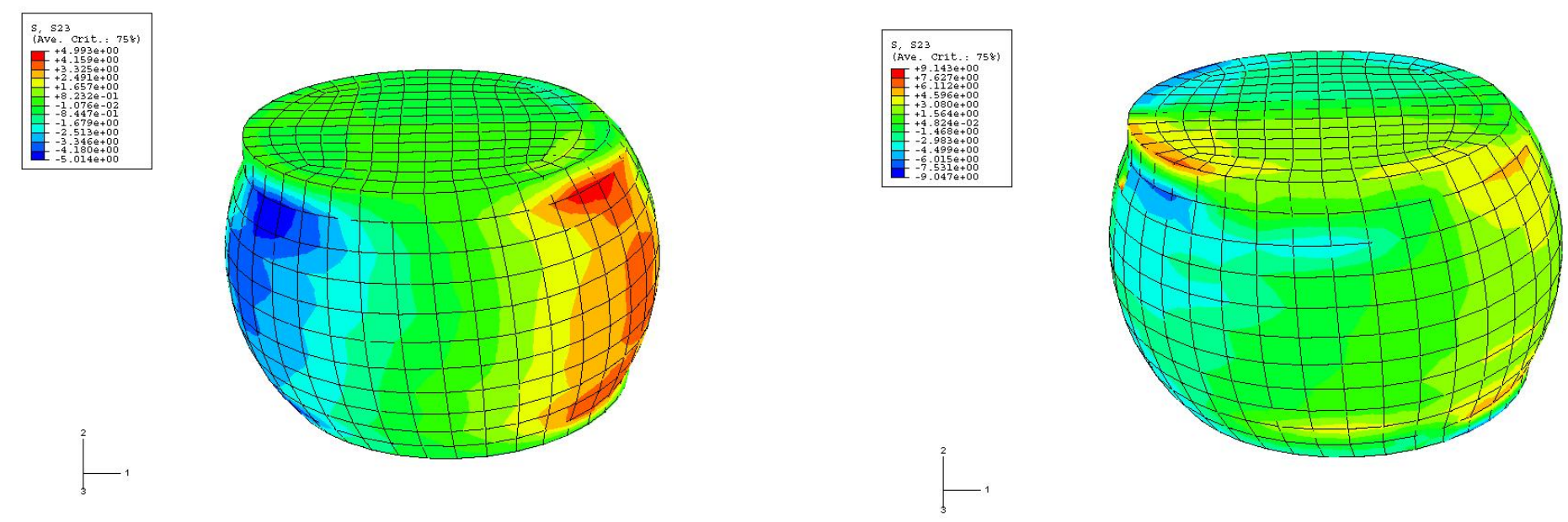

- Stress components are different when the grain orientation varies 


\section{Results for bi- and multi-crystalline}
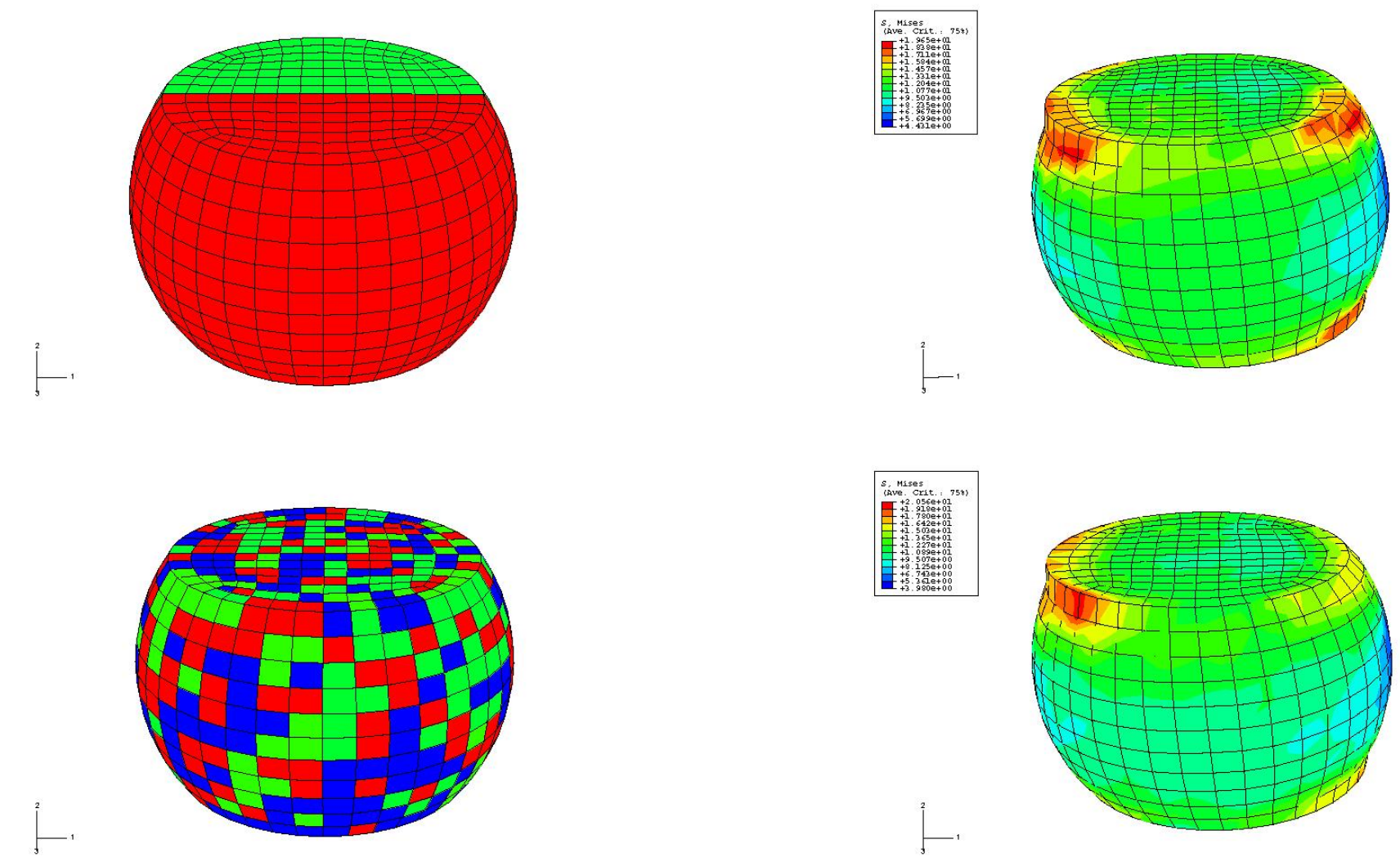

8 


\section{Conclusions}

- From the size of $100 \mu \mathrm{m}$ to $1000 \mu \mathrm{m}$, the small a solder joint is, the less number of grains it contains.

- The faster a cooling rate is applied, the finer substructure in the solder grains is obtained. However, the size of grain is not significantly sensitive the cooling rate in the range of $0.13^{\circ} \mathrm{K} / \mathrm{s}$ and $4.5^{\circ} \mathrm{K} / \mathrm{s}$.

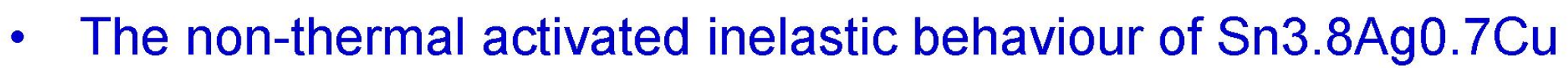
grains is considerably lattice-dependent for a micro-joint. 


\section{Thank you!}

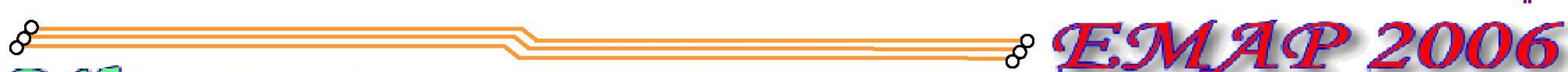

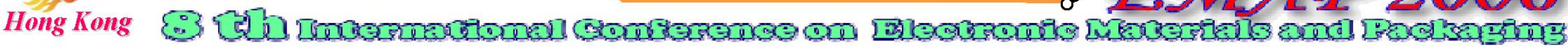

